\title{
Negociaciones posibles: visibilidad, vejez y parentesco entre mujeres que mantienen relaciones sexo-afectivas con otras mujeres'
}

\author{
Andrea Lacombe \\ Pagu, University of Campinas², Campinas/SP, Brazil
}

\section{Resumen}

En las últimas décadas se han sucedido cambios significativos en lo que respecta a las sociabilidades de las comunidades LGBT. En países de América Latina, el desarrollo de legislaciones referentes a la unión entre personas del mismo sexo, el reconocimiento legal de las identidadestrans y las políticas contra la discriminación y la violencia motivadas por la orientación sexual o por la identidad de género evidencian importantes transformaciones jurídicas y sociales. Estas políticas generan, al mismo tiempo, cambios profundos en las subjetividades y modos de socialización, marcando diferencias importantes que pueden colaborar en una mayor aceptación social de la comunidad LGBT. A partir de la investigación de campo realizada en las ciudades de Buenos Aires y São Paulo en el año 2013 y parte de 2014, el objetivo de este trabajo es entender la especificidad de las formas contemporáneas de sociabilidad de mujeres que mantienen relaciones homo-afectivas, con una edad de entre 40 y 70 años de edad, y los efectos que los últimos cambios legales pueden, o no, ejercer en los modos de vivenciar su sexualidad.¿Utilizan las prerrogativas de la ley de matrimonio o del fallo del STF? ¿Quiénes lo hacen?

Palabras clave: lesbianismo, generación, estudios de género y sexualidad, antropología urbana, América Latina.

\footnotetext{
1 Parte de este texto fue presentado en la $29^{\circ}$ Reunión de la Asociación de Antropología Brasileña, GT 76: Sexualidade, gênero e parentesco: permanências e transformações contemporâneas. Coordinadores: FlávioLuizTarnovski y Anna Paula Vencato.

2 Este artículo está basado en el trabajo de campo posdoctoral realizado actualmente en el Núcleo de GêneroPagu/Unicamp sobre regímenes de visibilidad, cambio social e convenciones sobre sexualidad y envejecimiento entre mujeres que mantiene relaciones homosexuales en São Paulo y Buenos Aires. Agradezco a la Fundação de Amparo à Pesquisa do Estado de São Paulo, Fapesp, por el financiamiento que permite la realización de esta investigación.
} 


\section{Resumo}

Nas últimas décadas têm acontecido mudanças significativas nas sociabilidades e visibilidades das comunidades LGBT. Em Latino-américa o desenvolvimento de legislações relativas à união entre pessoas do mesmo sexo, o reconhecimento legal das identidades trans e as políticas em contra à discriminação e a violência motivadas pela orientação sexual ou a identidade de género evidenciam importantes transformações jurídicas e sociais. Estas políticas geram, ao mesmo tempo, mudanças profundas nas subjetividades e modos de socialização, marcando diferenças importantes que possam colaborar na melhor aceitação social da comunidade LGBT. A partir da pesquisa de campo realizada nas cidades de Buenos Aires e São Paulo no ano 2013 e parte do ano 2014, o objetivo desta apresentação é entender a especificidade das formas contemporâneas de sociabilidade de mulheres, dentre 40 e 70 anos de idade, que mantêm relações homo-afetivas e os efeitos que as últimas mudanças legislativas podem ou não exercer nos modos de vivenciar sua sexualidade. São utilizadas as prerrogativas da lei de matrimonio ou a sentencia do STF? Por quem?

Palavras-chave: lesbianismo, geração, estudos de gênero e sexualidade, antropologia urbana,Latino-américa. 


\section{Negociaciones posibles:}

\section{visibilidad, vejez y parentesco entre mujeres que mantienen relaciones sexo-afectivas con otras mujeres ${ }^{3}$}

\section{Andrea Lacombe}

En las últimas décadas se han sucedido cambios significativos en lo que respecta a las sociabilidades de las comunidades ${ }^{4}$ Lésbicas, Gays, Bisexuales y Trans (LGBT). En países de América Latina, el desarrollo de legislaciones referentes a la unión entre personas del mismo sexo, el reconocimiento legal de las identidades trans y las políticas contra la discriminación y la violencia motivadas por la orientación sexual o por la identidad de género evidencian importantes transformaciones jurídicas y sociales. Vale la pena destacar que, en la región, estas agendas comenzaron a desarrollarse durante los años 1970 en un contexto socio-histórico marcado por las más cruentas dictaduras militares, momento en el que emergieron movimientos políticos y culturales en la lucha contra las opresiones de dichos gobiernos. A su vez, el impacto de la epidemia del HIV/sida, en los años 1980, complejizó más aún el campo político de los derechos civiles de las comunidades LGBT, llevando en un primer momento la discusión al terreno de la salud pública y, posteriormente, hacia la de los derechos civiles. Este proceso posibilitó el fortalecimiento de los movimientos LGBT visibilizados en las marchas del orgullo, lugar de exposición pública de sus reclamos legales, hoy incluidas en las agendas culturales de muchas ciudades del mundo. Estas políticas generaron, al mismo tiempo, cambios profundos en las subjetividades y modos de socialización, marcando diferencias importantes en las últimas dos décadas que culminaron en la posibilidad de mayor aceptación social de las comunidades LGBT.

Estos logros responden al agenciamiento político de las organizaciones feministas y LGBT cuyas agendas de visibilidad consiguieron posicionar a la ciudanía plena de dichas comunidades como tema fundamental del debate público y político. En Argentina, particularmente, los últimos años han sido incuestionablemente históricos en el camino por la reivindicación de los derechos sexuales. La modificación, en 2010, del Código Civil para permitir el casamiento entre personas del mismo sexo -y paralelamente la adopción- y la aprobación de una ley de identidad de género, pionera en el mundo por el hecho de no medicalizar ni judicializar las identidades autopercibidas, coloca al país en la vanguardia legislativa mundial. En Brasil, a su vez, el casamiento entre personas del mismo sexo fue posibilitado por la vía judicial, a través de una decisión del Supremo Tribunal Federal que, en el año 2011, homologó las uniones civiles con el matrimonio.

\footnotetext{
3 Parte de este texto fue presentado en la $29^{\circ}$ Reunión de la Asociación de Antropología Brasileña, GT 76: Sexualidade, gênero e parentesco: permanências e transformações contemporâneas. Coordinadores: FlávioLuizTarnovski y Anna Paula Vencato.

4 Uso este concepto pensando en la noción de "comunidades imaginarias" de Benedict Anderson (1991) y en el uso que Facchini (2008) hace para pensar las “comunidades lésbicas" o las "comunidades LGBT" formadas por redes de mujeres que comparten sus propias escenas, medios o comunidades y sus propios "lugares", estructuradas más allá del circuito de sociabilidad y entretenimiento.
} 
A partir de la investigación de campo realizada en las ciudades de Buenos Aires y São Paulo en el año 2013 y parte de 2014, el objetivo de este trabajo es entender la especificidad de las formas contemporáneas de sociabilidad de mujeres que mantienen relaciones homo-afectivas, con una edad de entre 40 y 70 años de edad, y los efectos que losúltimos cambios legales pueden, o no, ejercer en los modos de vivenciar su sexualidad. ¿Utilizan las prerrogativas de la ley de matrimonio o del fallo del STF? ¿Quiénes lo hacen? Más allá de las idiosincrasias propias de cada país, existen similitudes entre Brasil y Argentina, atribuidas, principalmente a la aparición de los movimientos homosexuales. En el año 1969 fue fundado, en Buenos Aires, el grupo Nuestro Mundo- que posteriormente, en 1971, dio lugar al mítico Frente por la Liberación Homosexual (FLH). En São Paulo, a su vez, el grupo Somos se fundó a finales de la década de 1970, nombre inspirado en la revista homónima que publicara el FLH. Ese contexto histórico de las décadas de 1970 e inicios de 1980 es un marco de referencia importante que funciona a modo de "bisagra" en los cambios de las subjetividades y moralidades, configurándose como uno de los motivos de la elección de la franja etaria del universo analizado en una tentativa de hilvanar narrativas de personas cuya sociabilidad puede incluir este período histórico, con políticas de representación y reconocimiento de derechos en la región.

\section{Según pasan los años. Curso de vida y envejecimiento}

De acuerdo al "paradigma del curso de vida", los cambios históricos y culturales alteran los patrones de desarrollo y transición en la vida adulta de diferentes grupos, generaciones y cohortes. Si partimos de este paradigma, explica Julio Simões (2004), cualquier punto de la trayectoria de vida precisa ser analizado desde una perspectiva dinámica, como consecuencia de experiencias pasadas y expectativas futuras, y de una integración entre los motivos personales y los límites del contexto social y cultural correspondiente: en este caso en particular, dos ciudades sudamericanas como São Paulo y Buenos Aires, polos socioculturales de la región. Guita Debert (1998) explica, a su vez, que las formas por las cuales la vida es periodizada, las categorías de edad presentes en una sociedad y el carácter de los grupos etarios que en ella se constituyen, son material privilegiado para pensar la producción y la reproducción de la vida social. Las categorías de edad son constitutivas de realidades específicas "siendo que operan recortes en el todo social, estableciendo derechos y deberes diferenciales en una población, definiendo relaciones entre generaciones y distribuyendo poder y privilegios" (Debert, 1998: 53).En su investigación sobre homosexualidad masculina y envejecimiento, Murilo Mota (2009) resalta la necesidad de considerar las representaciones estereotipadas, construidas y alimentadas por cierta homonormatividad que caracteriza a la vejez con demérito e impone cierto ideal de ser gay validado en un patrón corporal de juventud, consumo y masculinidad (2009:31). Según Pocahy (2008), la homonormatividad es otra forma de exclusión y de manutención de las regulaciones en torno a los binarismos de género y a la sexualidad vista como normal, en la intersección entre edad, raza/etnia y clase social. Sin embargo, Julio Simões remarca los cambios que se han sucedido en la sociabilidad de hombres homosexuales maduros, llamando la atención a un proceso de "luchas en torno de las narrativas legítimas con respecto a la relación entre cuerpo, envejecimiento y el sentido de sí mismo (...) en lo que respecta a la posibilidad de convertir la etapa más avanzada de la vida en una meseta indefinidamente extensa de consumo activo y agradable (2004: 420). En este sentido, Andrea Moraes (2009) plantea la inscripción 
generacional configurada como "un campo de posibilidades" (Velho, 1994) para la construcción de formas de ser homosexual siendo que, en el caso particular de la homosexualidad femenina, una mirada generacional permite recuperar el lugar que la sexualidad ocupa en la construcción de las trayectorias de vida. La vejez es vista por Moraes como una oportunidad abierta para rememorar y construir la madeja de la historia. La vejez es, simultáneamente, el tiempo en que esa historia se mantiene y se conecta con proyectos futuros, constituyéndose, por lo tanto, en un momento de creación (Lins de Barros, 1998). En este contexto me pregunto si, entre mujeres, también es posible pensar en un sistema donde, tanto la exaltación de la juventud, como de la experiencia adquirida a través de los años otorgan agenciamientos particulares a las diferentes franjas etarias.

La vejez de mujeres que mantienen relaciones homoafectivas adquiere, en esta perspectiva, particularidades en relación al contexto sociocultural y político en donde el reconocimiento social que implica la posibilidad de formalizar legalmente la unión entre personas del mismo sexo puede significar, también un reblandecimiento de los estigmas sociales con respecto a las vivencias erótico-afectivas entre mujeres. ¿Esa apertura, sin embargo, influye en las convenciones sociales de estas mujeres sobre la vejez?

\section{Cuando lo posible no siempre es lo deseable}

Mañana de lunes de julio en Buenos Aires. El viento sur que parece traer el mismísimo hielo de la Antártida se arremolina entre las personas que esperan, en la vereda del Registro Civil de Parque Centenario, la orden de la jueza para poder entrar en la sala de casamientos y acompañar a Miriam y Ester en la celebración de su unión. Miriam y Ester se conocieron un año antes en los "encuentros de los martes", como son conocidas las reuniones del grupo de reflexión para mujeres lesbianas organizadas por la ONG Puerta Abierta."Decidimos casarnos porque ahora tenemos un gobierno que, por suerte, nos reconoce frente a la ley. Ahora podemos protegernos, compartir la obra social y si algo le pasa a alguna de las dos la otra puede acompañarla y decidir legalmente qué medidas tomar”, me explica Ester y continúa relatándome historias de amigas que no pudieron entrar en el hospital a visitar a sus compañeras porque la familia de las otras no se los permitía. "Por suerte nuestras familias saben [que ellas dos están juntas] y lo aceptan", cuenta con una sonrisa en la cara.

Miriam tiene algo más de 50 años y Ester se acerca a los 70. Miriam afirma que la diferencia de edad fue más chocante para su madre y sus hijas que el hecho de empezar a salir con una mujer. "Su madre", agrega Ester riendo, "me dice 'esa señora”. En la sala hay muchas integrantes del grupo de reflexión, las más antiguas frecuentadoras que son amigas de Ester desde hace varios años, entre ellas, dos matrimonios que también se conocieron en el grupo coordinado por Graciela y Silvina, su pareja, testigo de casamiento de Ester.

Puerta Abierta comenzó sus actividades en 1999 como un espacio de psicólogos especializados en asuntos sobre sexualidades diversas. En el año 2009 fundó el primer centro de jubiladas y jubilados LGBT de América Latina. Mi aproximación fue justamente por ese motivo, sin embargo, al conversar con una de las coordinadoras del lugar supe que el centro ya no funcionaba como tal por requerimiento de las propias participantes “deseosas de socializar con mujeres más jóvenes”, según palabras de Graciela, la directora del lugar, para aumentar la posibilidad de encuentros amorosos. En el tiempo en que frecuenté el lugar (entre marzo y julio de 2013) la dinámica consistía en un grupo de reflexión que funcionaba todos los martes a las 19 hs con un costo mensual de \$300 ( $\mathrm{\$}$ 100, en ese momento) reunión que generalmente se extendía 
cenando en un restaurante a dos cuadras del lugar. Ese grupo funcionaba como un espacio de pertenencia y contención frente a la falta de comunicación que muchas de las integrantes tienen con sus familias de origen. Salir del closet es uno de los objetivos explícitos de las coordinadoras, el cualno es compartido por todas las participantes del grupo de reflexión.

El trabajo de campo en São Paulo me condujo hasta el bar Vermont. Emplazado en la planta baja de un edificio localizado en el ItaimBibi, un barrio de clase media y media alta, el Vermont tiene un público de edad variada, dependiendo del día en que se lo visita. Los domingos, día en que centré mi trabajo etnográfico, es frecuentado mayormente por mujeres de una franja etaria amplia, entre 30 y 60 años.

En esa convivencia dominical conocí un grupo de alrededor de 10 mujeres cuya media de edad era de 50 años, algunas comerciantes o con cargos gerenciales en empresas y otras jubiladas de diferentes bancos, con quienes conversé sobre relaciones sexo-afectivas, preferencias a la hora de pensar pareja, engaños y desengaños amorosos. Algo que llamó mi atención en las conversaciones que tenía con ellas, pero también con otras frecuentadoras del lugar de la misma franja etaria, fue el desinterés que mostraban por la conyugalidad como un deseo para sí, a diferencia de las más jóvenes (entre 30 y 35 años de edad). Cuando salía el tema (o yo lo iniciaba) las de mayor edad inclusive aconsejaban a las más jóvenes que fueran con cuidado, "con pie de plomo" a la hora de pensar en casarse y en "saltar de una casa a la otra" [de una relación con convivencia a la otra] y que aprendieran a "vivir la vida".

La posibilidad de acceder al casamiento supone, para algunas, una responsabilidad que "las jovencitas no tienen" ya que "se casan y separan muy rápido sin darle ninguna importancia ni significado al papel", explica Fabi quien tiene algo más de 55 años, es bancaria jubilada y frecuentadora asidua del Vermont: "yo sólo me casaría si estuviera viviendo con alguien desde hace por lo menos 10 años y tuviésemos bienes para heredar la una a la otra. No sé por qué quieren casarse con papeles si vivir juntas también es un modo de casamiento. No tienen nada que heredar, ni una relación de años para cuidar". Fabi dice que ella no es la "típica del ambiente que se casa rápido. Yo nunca me casé, nunca quise convivir con mis parejas. Creo que está buena la posibilidad de formalizar una unión, de protegerse y proteger los bienes, pero casarse por casarse... esa juventud está extrapolando un poco las cosas, me parece". Para Fabi, la conyugalidad no aparece como un valor, sin embargo reconoce el agenciamiento de contar con la posibilidad del matrimonio para aquellas que mantienen una relación estable. Para ella, la agencia está justamente en saber que las relaciones sin convivencia son una opción tan válida como el casamiento o la conyugalidad.

Conversaciones similares aparecieron con algunas de las frecuentadoras de más edad de Marlene, fundado en 1990 como centro cultural y establecimiento de diversión nocturna. Localizado en el barrio de Boedo, en Buenos Aires y muy cerca de Puerta Abierta, siempre funcionó como un espacio de encuentro y sociabilidad para lesbianas. Con diversas modificaciones a lo largo de estos años (con cambio de dueñas, inclusive), continúa siendo un lugar exclusivo para mujeres (la política de no dejar entrar hombres fue mantenida por la nueva administración), con una clientela de clase media baja y trabajadora, actualmente con edades entre 25 y 60 años. Las clientas con las que conversé desestimaban la convivencia con sus parejas aún estando en relaciones "serias". Prefieren, al igual que Fabi, mantener casas separadas porque ese es un modo de "conservar la libertad".

Bastante diferente era la situación en el grupo de reflexión de Puerta Abierta donde las relaciones sexoafectivas con morada conjunta aparecían en el universo de expectativas, incluso como un anhelo de gran parte de las concurrentes, y el casamiento siendo la reafirmación de ese vínculo. En los 4 meses de trabajo de campo presencié un casamiento, supe de otro que estaba gestándose y de dos más que habían sido en 2012 y comienzos de 2013·¿Por qué se establecen esas diferencias?¿Cuál es la carga simbólica atribuida a la institución del casamiento, tanto a la formalización de la unión frente al Estado como a la convivencia sin necesidad de ese acto performático y legal? 


\section{Los matices de la [in]visibilidad}

Silvia, también frecuentadora de Puerta Abierta y vieja amiga de Ester, convivió durante 25 años con Laura, su pareja, hasta que esta murió de cáncer, hace 4 años.

Tuve algunas relaciones largas, pero no eran completas porque no compartíamos todo ya que no convivíamos. La convivencia hace que una pareja esté completa; nosotras [con Laura] teníamos un grupo de amigas con el que hacíamos de todo: ir al cine, a cenar, a bailar, salir de vacaciones. Cuando salió la ley de matrimonio me puse feliz con las personas que podrían usarla. Con Laura tuvimos que arreglárnosla como pudimos con el tema de la herencia, hicimos acuerdos privados sin que su familia supiera, testamentos, pero casarnos no estaba en nuestros planes, ni siquiera pensábamos en eso, estaba fuera de nuestro universo... o nosotras fuera de él, en realidad, ¿no?

¡La ley de matrimonio igualitario me parece maravillosa!, exclama Isabel ${ }^{5}$ una psicoanalista de 70 y pocos años que vive en Buenos Aires "desde siempre".

Es una especie de sello, ¿viste esos sellos de goma?, que legaliza y de alguna manera obliga culturalmente a la sociedad a aceptar lo que es un hecho medio clandestino. Es posible que con Marga [actual pareja] nos casemos. Más que nada porque sería más barata la cuestión de las prepagas; ahora cada una tiene la suya y es muy caro. También por la cuestión de la herencia, porque este departamento está a nombre mío por hechos que no importan, y yo tengo una hermana que no es heredera forzosa pero tengo que desheredarla porque si no hereda ella y es absurdo porque tiene 10 veces más dinero que yo y no necesita heredar nada de mí. Entonces hice un testamento que tiene validez legal. Podría tenerla todavía más si hago certificar mi firma por un escribano, pero el testamento hológrafo, o sea manuscrito, donde además conste la palabra "esto es un testamento" para que no haya que deducir ni demostrar que es un testamento. Entonces la nombro a Marga única heredera. Ella no tiene demasiadas ganas porque su hermana tampoco sabe [que es lesbiana]. O sea ¡lo recontra sabe! pero entre ellas, que se quieren mucho y son muycercanas, no como yo con la mía, es algo no hablado. Entonces un casamiento oculto, clandestino, o sea a espaldas es feo. No es problemático, es feo, para ella es feo. La otra es deschavarse. Salir del armario, del placar o no sé bien de dónde uno se supone que sale, y decirle: ¡Soy gay!, como en las películas [risas]. ¿No es cierto? Y es difícil, pero... sí, es posible que lo hagamos...

Los testimonios exhibidos hasta el momento dan cuenta de diferente estrategias desarrolladas en el momento de pensar, por una lado las relaciones sexo-afectivas y, por el otro, el envejecimiento frente a esa producción continua de la diferencia con respecto a las prácticas identitárias normativas. Parte de estas estrategias están relacionadas con ciertos regímenes de visibilidad e invisibilidad que dan cuenta de éticas sobre la intimidad y la expresión del afecto y del deseo. ¿Qué significa, en los contextos investigados, exhibir para otros los modos de vivenciar la sexualidad? ¿Cuáles son las implicancias de ese acto? ¿Ante quién hacerlo?

En su libro "Los últimos homosexuales", el sociólogo argentino Ernesto Meccia (2010) desarrolla dos tipos ideales posibles para comprender los cambios históricos sobre la socialización de hombres que mantienen relaciones sexo-afectivas con otros hombres en las últimas décadas de ese país: el paradigma homosexual y el paradigma gay. El primero,

5 Isabel forma parte de una red de amigas y conocidas de una amiga porteña que me facilitó el contacto y, con ello, el acceso a esa red. 
explica Meccia, "se caracterizó por la participación casi ineludible de una misma colectividad de destino" (2010: 104), comprendiendo una experiencia pre-reflexiva al respecto de la homosexualidad, cuando los sujetos "no tenían un capital cognitivo alternativo al dominante del discurso heterosexual" (ibídem).

De este modo, la pertenencia a la colectividad no guardaba relación con los atributos socioeconómicos o políticos, era una "comunidad de destino". "Aún cargando sentimientos sombríos sobre su propio desarrollo social, ese modo de vida dual (conocido y clandestino) tuvo la particularidad de promover un sentimiento de pertenencia o alguna cosa parecida con una raza maldita a cuyo destino general no podían resistirse los destinos individuales (Meccia, 2010: 105). En la fase intermedia entre ambas lógicas, que comprende la segunda mitad de los años 1980 y la primera de los años 1990, la colectividad comienza a reconocerse en tanto discriminada. Aparece en escena la política de la visibilidad que aporta recursos lingüísticos para enunciar esa discriminación. Finalmente, la lógica gay se caracteriza por la mercantilización de las mediaciones de gestión de la identidad social y personal pasando de una sociabilidad anodina vehiculada en territorios clandestinos a otra cuya clave es la multiplicidad de ofertas que segmentan el colectivo sociocultural, económica y generacionalmente. El cambio de lógicas trae aparejada, para Meccia, la gaycidad acompañada del orgullo, el reconocimiento y la visibilidad social fruto de la consecución de los derechos civiles por parte del movimiento LGBT.

Sin embargo, si pensamos las sociabilidades investigadas en este trabajo de campo a partir de este modelo socio-histórico de explicación, las lógicas referentes a los criterios sobre visibilidad e invisibilidad, tanto como las auto-referencialidades -como veremos más adelante en este texto- parecen discordar un poco de los diferentes paradigmas que dan cuenta de interrelaciones entre hombres más que entre mujeres, manteniendo relaciones homoafectivas.

Podemos pensar, entonces, en la convivencia de dos lógicas de sociabilidad que constituyen una trama de inteligibilidad social e intergeneracional que se ajuste más a las particularidades de las relaciones analizadas, tanto en el contexto paulista como en el porteño. La primera está asociada a la intimidad y podríamos llamarla lógica del recato, o lo que Paiva (2007) denomina como ética de la reserva y de la invisibilidad, "una recusa de evidencias plenas mediante la rarefacción de los regímenes de visibilidad de la relación y el uso de estrategias de restricción de la expresividad que garantizan un 'margen' de reserva/distancia psicológica, que protegen las relaciones de una visibilidad ostensiva y que imponen un régimen de enunciabilidad bastante variable, conforme las situaciones y los agentes interesados" (Paiva, 2007: 24 n1). A la hora de analizar,en su tesis de doctorado, las sociabilidades de mujeres con relaciones homoafectivas en São Paulo, Regina Facchini también describe una "compleja negociación del 'secreto', envolviendo una postura 'discreta' en relación a la homosexualidad donde la categoría 'discreción' desempeña un papel fundamental a la hora de negociar relaciones familiares y profesionales mediante un juego de enunciados y silenciamientos" (2008: 243-244), tal y como podemos observar en la disquisición de Isabel con respecto al casamiento como una opción para ella y su pareja. La segunda lógica está asociada a la visibilidad y se aproxima más a la caracterización del paradigma gay de Ernesto Meccia, caracterizada anteriormente dentro de la cual podemos enmarcar, por ejemplo, el casamiento de Miriam y Ester y la modalidad que las coordinadoras quieren imprimirle a las reuniones del grupo de reflexión lésbica de Puerta Abierta, pero también en la opción de Fabi que elije no convivir con sus parejas. 
¿Qué tipo de negociaciones son posibles, entonces, a la hora de hilvanar deseo, cuidado de la intimidad y herencia? ¿La visibilidad aparece en el horizonte como un mandato político y social o como una gestión de los sujetos frente a la necesidad de resguardarse a sí mismos y a sus parejas? En este sentido, y así como las estrategias utilizadas para dar cuenta de relaciones de difícil denominación desafían representaciones y prácticas que escapan a las estructuras tradicionales de familia, el acceso al matrimonio para personas del mismo sexo pone en tela de juicio las estrategias adoptadas para mantener los bienes de la pareja sin tener que explicitar la orientación sexual o formalizar la unión, pero también se vislumbra como una posibilidad de dar cabida a otro tipo de nociones de familia, pensadas horizontalmente, donde la amistad sustituye las conexiones biogenéticas o las relaciones culturales en tanto relaciones de parentesco.

Gabriela y Laura viven juntas hace más de 6 años. Ya fueron pareja 10 años atrás y ahora, siendo amigas son herederas la una de la otra. "Nuestro vínculo es más familiar que otra cosa. Somos el soporte la una de la otra y cuando alguna falte queremos que sea la otra quien se quede con los bienes y no nuestros hermanos o sobrinos que no logran entender nuestro vínculo porque nosotras tampoco les explicamos bien nunca. Es a ella que le dejaré estas cuatro paredes que están a mi nombre y si es necesario nos casaremos para que no haya problemas, aunque ya no estemos juntas como pareja”, me explica Gabriela. Ambas tienen un poco más de 50 años, viven en el cono-urbano bonaerense y suelen frecuentar Marlene. El parentesco puede ser rediseñado en función de otro tipo de lazos igualmente duraderos como las amistades, eje de análisis tanto de Kate Weston (2003), como de Judith Butler (2006). En este sentido, Fonseca al hablar sobre homoparentalidad argumenta que, aún sin ser muy diferente de otro tipo de relaciones familiares, "ayuda a resaltar ciertos elementos, temas que exigen debate, y cuyas repercusiones se extienden más allá de la familia gay o lésbica. Al final, ayuda a revelar las actuales formas familiares como 'co-producciones' que envuelven, además de valores culturales, leyes, tecnología y dinero. El parentesco se torna, así, una cuestión política y cultural, obligándonos a repensar "qué familias elegimos (o si de hecho queremos elegir alguna)" (Fonseca, 2008: 781).

Siguiendo esta línea de razonamiento, en el contexto de esta investigación la posibilidad del matrimonio entre personas del mismo sexo aparece como un ejemplo paradigmático de la convivencia entre ambas lógicas. Casarse significa hacer visible una unión y ese no es necesariamente el deseo de algunas de las mujeres con las que conversé, que prefieren continuar con arreglos previos y mantener el sigilo y la discreción sobre sus relaciones sexo-afectivas con otra mujer. Sin embargo, también puede ser una salida para darle forma a relaciones que son pensadas como "de familia", como la de Gabriela y Laura.La división visibilidad vs. invisibilidad no puede ser pensada monolíticamente, sino como una gestión singular y específica de los individuos entre la exposición y el ocultamiento.

Situacionalmente, la invisibilidad diseña, en diferentes escenarios, diferentes capas de sentido para las personas que la vivencian y para aquellas con las que conviven, pero también para las que optan por hacer pública su orientación sexual. En esta misma dirección, la elección por la visibilidad está matizada en diferentes niveles relacionados a los grados de intimidad que existen entre los sujetos. Para Isabel y Marga, los lucros económicos y burocráticos que el casamiento puede traerles son cuidadosamente evaluados con respecto al hecho de tener 
que dar cuenta de más de 20 años de relación frente a sus familias. El closet gay, argumenta KosofskySedgwick, "no es sólo una característica más de la vida de las personas gays. Para muchas de ellas es también una característica fundamental de la vida social" (2007: 22). El closet, de todos modos, no se constituye como una estructura monolítica y binaria sino, muy por el contrario, como niveles en los cuales las personas entran y sale ya que las "geografías personales y políticas son, antes que nada, imponderables y convulsivas del secreto abierto (ibid, 39). Vivir en el closet y, en un cierto momento, salir de él nunca son cuestiones puramente herméticas, explica Sedgwick. El juego de visibilidades e invisibilidades se esboza como una trama de capas superpuestas en las que siempre existe la opacidad y la transparencia, simultáneamente; ese closet de vidrio de lo no dicho, pero vivenciado, que confronta las nociones de privacidad y publicidad del fuero íntimo de los sujetos y sus relaciones.

Yo siempre estuve a favor del matrimonio, relata Sandra, trabajadora del área de la salud y frecuentadora de Marlene. "Luchaba, me peleaba y discutía que si un hombre puede casarse con una mujer, por qué no pueden hacerlo dos hombres o dos mujeres, por qué no tienen ese permiso, sabiendo que cuando una falta [muere] la otra persona tiene derecho a los mismos beneficios por haber estado juntos. En mi caso yo no tengo a nadie, pero si tuviera una compañera pensaría en el asunto, pero me da un poco de arrepentimiento también... haría un casamiento en casa y que nadie se enterara, ¿entendés? No sé por qué soy tan paranoica, yo nunca quise hablar de esto ni con un psicólogo, me mandaría traer un cura, o lo que sea que me fuera a casar, a mi casa y que nadie sepa, sólo los amigos, claro."

En la vida cotidiana la salida del closet no necesariamente aparece como un valor. En muchos casos la invisibilidad supone una estrategia consciente y optativa (contrariamente a la obligatoria), un modo de agencia en la que los niveles de constitución identitaria se relacionan con nociones de moral específicas en consonancia con la ética de la reserva expuesta anteriormente a partir de Paiva. Sin embargo, y como pone de relieve Heilborn, este modo de pensar el closet "ha suscitado una viva discusión por parte de los actores comprometidos con el movimiento de afirmación homosexual. La afirmativa de que la declaración explícita de la orientación homoerótica no es considerada necesaria y, sobre todo, es entendida como limitadora de las potencialidades de los individuos, despierta sospechas frecuentemente atribuidas al miedo del estigma, a la cobardía frente a las convenciones sociales, a una estrategia calculista del anonimato, o incluso a la falta de solidaridad entre 'iguales"' (1996: 4). De acuerdo con esta perspectiva, la visibilidad puede ser considerada -contrariamente a los atributos que los "actores comprometidos" le otorgan- como una publicitación de actos del dominio de lo íntimo y, por lo tanto, de la esfera de lo privado, dependiendo de las trayectorias familiares y de la edad en donde nociones como discreción, recato o intimidad adquieren ribetes diferenciados, sinónimos de cuidado y contención.

\section{El discreto encanto de entender}

Discreción, por ejemplo, es una categoría accionada por alguna de las entrevistadas a la hora de explicar los términos que usan para auto-referenciarse. Silvia me cuenta que "antes teníamos todo un código para que los otros [personas heterosexuales] no entendieran y no nos molestaran. Better era una palabra usada para hablar de gente del ambiente y Paqui para referirnos a los otros, los héteros. Paqui por paquidermo, ¡porque eran unos pesados! y better porque éramos mejores que ellos”. Actualmente ella prefiere la palabra gay para auto-denominarse y referirse a otras mujeres que mantienen relaciones homoafectivas. Fabi, a su 
vez, prefiere la palabra entendida que usa desde que llegó a São Paulo a los 17 años y comenzó a frecuentar establecimientos nocturnos orientados al público LGBT. Entendida, para ella, significa conocer algunas cosas que otras personas no conocen y, por lo tanto pertenecer a un círculo diferente. Creo necesario dejar claro que ambas hablaron con sus familias, hace mucho tiempo, sobre sus preferencias por mujeres y en algunos trabajos en los que estuvieron. Sin embargo, a la hora de pensar en las palabras con las que denominan esa preferencia, "lesbiana" está fuera de su universo de referencias por ser "muy fuerte" y tener relación con un "discurso médico" o político.

En entrevistas, una realizada en Buenos Aires y otra en São Paulo, con dos mujeres que tuvieron participación en grupos de activismo feministas o LGBT en sus trayectorias de vida, la palabra lesbiana aparece con un fuerte contenido político. Alicia, periodista porteña de 48 años, explica que reivindica para sí la palabra lesbiana como una identidad política. Ella fue la creadora del suplemento LGBT de uno de los principales periódicos de tirada nacional de Argentina. Gaby, paulista de 50 y pocos años, con un pasado en grupos feministas del PT, a la hora de ser interrogada sobre la palara que usa para definir su orientación sexual, responde rápidamente lesbiana, pero luego establece la diferencia entre "una auto-denominación pensada como identidad política y de pertenencia" [lesbiana] y otra utilizada en el grupo de amigas [sapa].

Esos son algunos ejemplos con los que me encuentro en el campo; términos que tienen sentido en detrimento de otros. Que entiende, chongo, torta, femme, del ambiente, gay o minita ganan fuerza de referencialidad y auto-identificación, desmantelando la carga semántica de lesbiana. Luis Aquino ya llamaba la atención sobre la recusa por el término entre las integrantes de su campo de investigación en Porto Alegre por su connotación peyorativa y acusatoria (1995: 82). Aquino destaca, sin embargo, que la categoría es accionada por las "homosexuales feministas que, al reconocerse así, tratan de enfatizar el aspecto político de la opción homosexual: la recusa, en la práctica, de la relación de poder establecida por la heterosexualidad, donde el hombre domina a la mujer" (ibid: 83).

Facchini también llama la atención a la modificación del uso del término entendida que pierde uso en el grupo donde fue acuñado y gana centralidad en la clase baja. No obstante, si esa división es pensada en relación con la franja etaria, la categoría recobra su carga semántica, incluso entre los sectores de clase media, como es el caso del Vermont. Si pensamos esa situación como un prisma, los términos émicos son los que aparecen del lado donde la luz, como un arcoíris, se descompone en diversos espectros; el término lesbiana en tanto categoría política y científica es, a su vez, el haz blanco que recompone en uno solo los demás, en un mecanismo óptico de representación. Lo que sigue preocupándome con respecto a los usos de la categoría de lesbiana es evitar caer en usos instrumentales del término que cristalizan determinados parámetros y los convierten en lo que Butler designa como "imperativos de la regulación" (2000: 91).

¿Por qué lesbiana debería tener mayor estatuto epistemológico que torta o gay, siendo que la primera pierde significado en el campo cuando no estamos delante de sujetos relacionados con el activismo feminista o LGBT? ¿Cuál es su fuerza y sentido? Esa preocupación se aplica tanto a la política como a la academia. En mayo del año 2013 tuvo lugar en la ciudad de Rosario, Argentina, la Celebración de las amantes, segundo "Encuentro de orgullo y disidencia lesbiana". En esa ocasión, Virginia Cano, filósofa lesbiana y feminista, como ella se auto-denomina, presentó el trabajo "Una exploración en torno a la lengua tortillera”, en una tentativa de pensar una cartografía que contemplase los modos de nombrar-nos como producciones de subjetividad

Aprendí, dice Virgina, lo eficaz que pueden ser las palabras y los modos de nombrar(nos). De llamar y clasificar nuestros modos de ser-con y de habitar este mundo. Las palabras, y las economías taxonómicas que las sostienen, son verdaderas tecnologías de producción subjetiva. Nos hacen ser quienes (no) somos y condicionan lo que hacemos, sentimos, pensamos, conocemos y deseamos. 
El texto de Cano trae a colación la necesidad de comenzar a pensar en el sentido político de la categoría lesbiana en relación a esos otros términos de auto-denominación que constituyen corporalidades y espacios de sociabilidad dentro del propio activismo y, de ese modo, darles otro significado político.

Analizar la relación entre las diferentes categorías de auto-referencialidad movilizadas en el campo y el tipo de sociabilidad que esos sujetos desarrollan permite observar una trama de sentidos que tiene al régimen de visibilidad/invisibilidad como punto nodal. Las narrativas que traigo en este texto indagan las convenciones sociales y estilos de vida desarrolladas en contextos urbanos por sujetos que transitan por mundos velados y muchas veces estigmatizados, cuyas trayectorias ayudan a comprender la organización de redes de sociabilidad en relación con otros fragmentos de lo social o -usando las palabras de Peter Fry en el prólogo de O negócio do Michê (Perlongher 1987)- para "cuestionar los lugares comunes del 'centro' de la sociedad". Estas trayectorias resaltan estrategias de negociación permanente entre las posibilidades de equidad civil que los cambios legislativos y judiciales traen aparejados y modos de vida en donde nociones como discreción, recato o intimidad adquieren ribetes diferenciados, sinónimos de cuidado y contención. Donde lo privado, no necesariamente quiere ser político. Para entender estas estrategias es necesario traer a consideración los modos como edad y generación operan en la conformación de las moralidades y las redes de sociabilidad. La relación entre las familias de origen, muchas veces atravesadas por el anonimato de la relaciones de conyugalidad homosexual o truncadas por la explicitación de una orientación sexual disidente, debe ser enmarcada en un contexto histórico donde la represión política y moral de las décadas de 1970 y parte de 1980 y el lugar de la mujer en tanto reproductora y ama de casa forman un entramado social en el que las amistades se transforman en comunidades de destino que cumplen el rol de relaciones de solidaridad, contención y familiaridad. Al mismo tiempo, el ejercicio político que algunas de las entrevistadas tiene y la publicitación de las agendas feministas y de los movimientos LGBT muestra una reflexión sobre los mandatos sociales de feminidad, recato y discreción, complejizando las tramas discursivas y poniendo en cuestión los modos de reproducción social de esos grupos de sociabilidad. Ese entramado social que he descripto, guarda características similares en los contextos investigados en ambas ciudades, distanciándose de los análisis realizados en las comunidades de hombres que mantienen relaciones homoafectivas en lo que respecta a la constitución de redes de amistad, afecto y sexo.

Recibió 31/03/2015, aprobada01/06/2015

\section{Bibliografía}

ANDERSON,Benedict. 1991(1983).Imagined communities:reflections on the origin and spread of nationalism. Londres: Verso.

AQUINO, R. Luis O. 1995. "Discurso lésbico e construções de gênero". Horizontes Antropológicos, 1(1):79-94.

BUTLER,Judith. 2006 (2004).Deshacer el género. Buenos Aires:Paidós. 2000. "Imitación e insubordinación de género" In: Grafías de Eros. Historia, género e identidades sexuales. Bs. As.. Edelp. pp. 87-113. 
CANO, Virginia. 2013. "Una exploración en torno a la lengua tortillera". Texto apresentadona "2da Celebración de las Amantes. Jornadas de orgullo y disidencia lésbiana”. Rosario, Argentina. Mimeo.

DEBERT, Guita. 2007 (1998). "A antropologia e o estudo dos grupos e das categorias de idade". In Velhice ou terceira idade? Myriam Lins de Barros (org.). Rio de Janeiro. FGV Editora. pp. 49-68.

FACCHINI, Regina. 2008. Entre umas e outras. Mulheres (homo)sexualidades e diferenças na cidade de São Paulo. Tese de doutorado em Ciências Sociais. Instituto de Filosofia e Ciências Humanas. UNICAMP. Campinas.

FONSECA, Claudia 2008. "Homoparentalidade: novas luzes sobre o parentesco". Estudos Feministas, $16(3): 769-783$.

FRY, Peter. 1987. "Prefácio" . In:NéstorPerlongher,O negócio do michê: a prostituição viril. São Paulo: Brasiliense. pp.11-16.

HEILBORN, Maria Luiza. 1996. "Ser ou estar homossexual: dilemas de construção da identidade social”. In: Richard Parker; Regina Barbosa (eds.),Sexualidades brasileiras. Rio de Janeiro: RelumeDumará. pp 136-145.

LINS DE BARROS, Myriam. 2007 (1998). "Testemunho de vida: um estudo antropológico de mulhres na velhice”. In: _-- (org.), Velhice ou terceira idade? Rio de Janeiro:FGV Editora. pp 113-168.

MECCIA, Ernesto. 2010. Los últimos homosexuales. Editorial: Gran Aldea, Buenos Aires.

MORAES, Andrea. 2009. "Fronteiras da relação. Gênero, geração e a construção de relações afetivas e sexuais". Sexualidad, Salud y Sociedad, 3: 10-32.

MOTA, Murilo. 2009. "Homossexualidade e envelhecimento: algumas reflexões no campo da experiência”. Sinais-Revista Eletrônica - Ciências Sociais,.06(1): 26-51.

POCAHY, Fernando. 2008. Marcas do poder: o corpo (do) velho-homossexual nas tramas da hetero e homonormatividade. Texto apresentado no "Fazendo Gênero 8 - Corpo, Violência e Poder". Florianópolis:mimeo.PAIVA, Antônio Crístian S. 2007. "Reserva e invisibilidade: a construção da homoconjugalidade numa perspectiva micropolítica”. In: Miriam Grossi, Anna Paula Uziel e Luiz Mello (orgs.), Conjugalidades, parentalidades e identidades lésbicas, gays e travestis. Rio de Janeiro:Editora Garamond.pp. 23-46.

SEDGWICK, EveKososfsky. 2007 (1993). "A epistemologia do armário”. Cadernos Pagu, 28: 19-55. SIMÕES, Julio. 2004. "Homossexualidade masculina e curso de vida: pensando idades e identidades sexuais". In:A. Piscitelli; M. F. Gregori; S. Carrara (orgs.), Sexualidades e saberes: convenções e fronteiras. Rio de Janeiro:Garamond. pp.415-447.

VELHO, Gilberto. 1981. "Projeto, Emoção e Orientação em Sociedades Complexas". In:Individualismo e Cultura: notas para uma antropologia da sociedade contemporânea. Zahar, Rio de Janeiro. pp. 13-37.WESTON, Kate, 2003. Lasfamilias que elegimos. Lesbianas, gays y parentesco. Barcelona:Editorial Bellaterra.

\section{Andrea Lacombe}

Pagu, University of Campinas, Campinas/SP, Brazil

andrealacombe@yahoo.com.br 